\title{
EL PAPEL ECONÓMICO DEL ESTADO: UNA CRÍTICA
}

\author{
JOSE HERNANDEZ CABRERA*
}

Fecha de recepción: 22 de mayo de 2016

Fecha de aceptación: 3 de octubre de 2016

Resumen: La justificación neoclásica del papel económico del estado descansa en conceptos tales como el modelo de economía en equilibrio, la competencia perfecta, los fallos del mercado, la eficiencia social y el análisis de coste-beneficio, los monopolios, las externalidades, la teoría de los bienes públicos y la existencia de free riders. Toda esta doctrina, que es utilizada por los economistas para justificar el intervencionismo, puede ser criticada desde los postulados teóricos y metodológicos de la Escuela Austriaca de economía. De este análisis obtenemos dos conclusiones: primera, muchos de los problemas atribuidos al mercado no son tales; segundo, no queda demostrado que la intervención del gobierno pueda mejorar el funcionamiento del mercado.

Palabras clave: Competencia perfecta, fallos del mercado, monopolio, externalidad, bienes públicos.

Clasificación JEL: B25, E61, H11, H42, H44, P48.

Title: The economic Role of the State: a criticism

Abstract: The neoclassical justification of the economic role of the state rests on concepts such as the model of economy in equilibrium, perfect competition, market failures, social efficiency and the cost-benefit analysis, monopolies, externalities, the theory of public goods and the existence of free riders. All this doctrine, which is used by economists to justify interventionism, can be criticised from the theoretical and methodological tenets of the Austrian School of economics. From this analysis we get two conclusions: first, many of the problems attributed to market are not such; second, it is not proved that the government intervention can better the market functioning.

\footnotetext{
* Teniente Coronel en la Reserva y Socio-docente en Somer Consulting. Doctorando en Economía de la Universidad Rey Juan Carlos.
} 
Keywords: Perfect competition, market failures, monopoly, externality, public goods.

JEL Codes: B25, E61, H11, H42, H44, P48.

\section{I \\ INTRODUCCIÓN}

Es una idea generalmente aceptada que el estado debe desempeñar un papel activo en la economía de una nación. «Si en algún ámbito se puede destacar el progreso del intento de construcción de una teoría positiva de la política económica, este es sin duda el de la intervención pública sobre la economía» (Bel, 2004: 233). Supuestamente, un elevado grado de intervención en la provisión de determinados servicios —llamados «públicos»—y uno menor en otras áreas de la economía, puede mejorar los resultados del mercado. El libre mercado - afirma la mayoría de expertos- tiene «fallos» y provoca perjuicios sociales tales como la concentración de la oferta (monopolio) y la explotación de los consumidores, la contaminación ambiental (externalidades negativas), la falta de equidad o la existencia de free riders (externalidades positivas) o "gorrones» que evitan pagar por aquello que consumen; esto último ocasionaría, eventualmente, que determinado tipo de bienes (públicos) se produjeran de forma insuficiente o que incluso no se produjeran en absoluto. Para dar un soporte científico a estas ideas los economistas keynesianos y neoclásicos elaboraron un modelo, llamado «equilibrio», que supondría una solución óptima al empleo de los recursos (Bastos, 2005: 16). Una vez ideadas una serie de exigencias teóricas de "perfección» de un sistema económico llegaron a la inevitable conclusión de que la realidad del mercado no satisfacía su modelo. Concluyeron sabiamente que la realidad económica estaba «equivocada» y que el mercado tenía «fallos» sin llegar a plantearse que, tal vez, fuera su modelo el equivocado (Huerta de Soto, 2004: 56). Sea como fuere, la verdad científica que se enseña en las cátedras y libros de texto es que el mercado, aunque funciona razonablemente bien, es una 
institución imperfecta que requiere de la acción correctora del gobierno.

El propósito de este trabajo es hacer una crítica económica y ética a todos los argumentos que justifican el papel económico del estado, desde los postulados teóricos, metodológicos y praxeológicos de la Escuela Austriaca de economía. En particular, analizaremos conceptos tales como competencia perfecta, monopolios, fallos del mercado, eficiencia social y análisis coste-beneficio, externalidades, teoría de los bienes públicos y la figura del free rider o gorrón.

\section{II}

\section{COMPETENCIA PERFECTA Y MONOPOLIO}

La teoría del monopolio constituye uno de los argumentos que justifica el papel económico del estado. A grandes rasgos, estas son las condiciones que definen el modelo de competencia perfecta (Frank, Jennings \& Bernanke, 2012: 157):

1. Todas las empresas venden el mismo producto normalizado.

2. El mercado tiene muchos compradores y vendedores, cada uno de los cuales compra o vende una pequeña fracción de la cantidad total intercambiada.

3. Los vendedores pueden entrar y salir del mercado fácilmente.

4. Los compradores y vendedores están bien informados.

Se reproduce aquí lo que Demsetz (1969) denominó como esquema «nirvana», que consiste en lo siguiente:

a) Se establece un modelo ideal o de "competencia perfecta».

b) Se detecta que, para un cierto tipo de bienes, en determinado momento y lugar, existe una concentración de la oferta que contradice al modelo.

c) El gobierno debe intervenir en la economía para hacer que la realidad se aproxime al modelo.

Algunos autores han pretendido dar validez al intervencionismo mediante falacias ad verecundiam, en particular, es criticable la 
tergiversación de la obra de Adam Smith y pretender equiparar la «mano invisible» del libre mercado con el esquema de competencia perfecta (Samuelson y Nordhaus, 2006: 34):

Adam Smith reconoció que las virtudes de los mecanismos de mercado se aprovechan plenamente sólo cuando están presentes los pesos y contrapesos de la competencia perfecta [...] La doctrina de la mano invisible se aplica las economías en las que todos los mercados son perfectamente competitivos, las cuales producirán una asignación eficiente de recursos.

El profesor Rodríguez Braun (2016), buen conocedor y traductor del economista escocés, corrobora esta «distorsión de Adam Smith, muy popular entre los economistas, debida entre otros precisamente a Samuelson». Bajo las premisas de la economía del «nirvana», encontrar «fallos» en forma de monopolio es algo inevitable.

\section{Teoría neoclásica del monopolio}

En la medida que el mercado se desvía de la situación de máxima eficiencia aparece la «competencia imperfecta o los mercados monopólicos». El resultado es una producción «demasiado» baja y un precio «demasiado» alto (Samuelson y Nordhaus, 2006: 34). Se afirma esto porque, supuestamente, existe un «precio competitivo» al cual se vende cierta cantidad de producto y que proporciona la mayor utilidad al consumidor. Si el monopolista o cártel de empresas detecta que al nivel del «precio competitivo» la curva de demanda es inelástica, aquél puede incrementar su beneficio a expensas de los consumidores. La forma de hacerlo sería reduciendo deliberadamente la oferta e incrementando el precio unitario. Dicho de otro modo, bajo el monopolio, la empresa fija un precio por encima de su ingreso marginal provocando una supuesta «explotación» al consumidor (Huerta de Soto, 2009-2010: tema 21). Bajo el modelo de «competencia perfecta» hay muchas empresas que venden un

\footnotetext{
${ }^{1}$ Consulta personal realizada al profesor Rodríguez Braun, el 17/04/2016.
} 
mismo producto (o muy similar) y si alguna de ellas incrementara el precio por encima de su nivel competitivo los consumidores optarían por comprar productos sustitutivos a sus competidores. Por tanto, la solución para que el monopolista no abuse de su «poder de mercado» es impedir la concentración de la oferta mediante prohibiciones a la fusión de empresas o creación de cárteles; y en el supuesto de que una empresa crezca de forma orgánica hasta alcanzar una dimensión de monopolio, se la podría trocear en muchas empresas de menor tamaño.

\section{Crítica austriaca al concepto neoclásico de monopolio}

Las principales objeciones a la teoría neoclásica del monopolio han sido expuestas por la mayoría de economistas austriacos: Bastos, 2005; Block, 2003; Hoppe, 2003; Huerta de Soto, 2010; Kinsella, 2008; Kirzner, 1995; Menger, 2013; Mises, 2011 y Rothbard, 2013a y 2013b; entre otros. Sin embargo, podemos identificar dos visiones austriacas del monopolio (Block 1977: 271). Para Mises y Kirzner el monopolio puede existir en el libre mercado y se produce una restricción deliberada de la oferta unida a un incremento del precio por parte del monopolista. Para Rothbard, y resto de autores, el monopolio consiste en un privilegio otorgado por el gobierno y es incompatible con el libre mercado.

Comencemos analizando qué es un monopolio. «Pocos son los economistas que hayan formulado una definición de monopolio que sea coherente y tenga significado» (Rothbard, 2013a: 164). Y puesto que los economistas de las distintas corrientes o escuelas tienen diferentes formas de entender qué es un monopolio, es preciso hacer una definición provisional. El origen etimológico de monopolio proviene de las palabras monos (solo) y polein (vender), es decir, el único vendedor de cierto bien. Esta definición es problemática por varios motivos:

1. A excepción de las materias primas o commodities, es muy difícil que dos empresas produzcan el mismo tipo de bien y, en todo caso, solamente el consumidor está en disposición de apreciar esta diferencia. En una economía moderna los productos físicos 
llegan al mercado ya elaborados y bajo determinadas marcas comerciales por lo que los consumidores pueden distinguir más fácilmente un producto de otro. En cuanto a los servicios, una característica es la variabilidad en la producción. No hay dos servicios iguales, ni siquiera los realizados por una misma persona. Todo médico, abogado, actor o profesor es un monopolista de sí mismo ya que nadie puede imitar su forma de trabajar.

2. El segundo problema es definir el ámbito geográfico al que correspondería el monopolio (Bastos, 2005: 32). A medida que restringimos aquél van apareciendo monopolios que antes no lo eran. A nivel mundial Repsol no es un monopolio pero a nivel nacional sí lo es. En España, Endesa no es un monopolio pero en Canarias es el único productor (importante) de energía. Cada territorio, en función de su población, es capaz de sostener un determinado número de productores que, en muchos casos, sólo es uno. En un pequeño pueblo, sólo hay negocio para una farmacia, un supermercado o una gasolinera.

3. El tercer problema es el ámbito temporal del monopolio. El concepto neoclásico de monopolio es estático pero la competencia es un proceso esencialmente dinámico (Huerta de Soto, 20092020: tema 21.3). Los economistas pecan de imprecisión al no determinar el lapso temporal preciso para que una empresa sea considerada monopólica (Bastos, 2005: 33). Por ejemplo, durante la crisis económica de 2008 muchas personas se vieron obligadas a vender sus joyas y surgió, en cada ciudad, un primer negocio de «compro oro». Este «monopolio» resultó ser efímero pues otros empresarios, atraídos por las ganancias, abrieron rápidamente otros negocios similares.

Según Rothbard (2013b: 22\%): «la única definición posible de un monopolio es una concesión de privilegios por parte del gobierno», tal y como afirmaba el gran jurista del S. XVII, Lord Coke (Rothbard, 2013a: 172):

Monopolio es el establecimiento $\mathrm{u}$ otorgamiento por parte del rey, mediante merced, concesión suya, o de otra manera [...] a cualquier persona o personas, cuerpos políticos o corporativos, para la ex- 
clusiva venta, compra, fabricación, elaboración o uso de alguna cosa, por medio de lo cual cierta persona o personas, cuerpos políticos o corporativos, resultan restringidos en cuanto a libertades que anteriormente tenían, o entorpecidos en su legítimo comercio.

En la actualidad, para los Austriacos, la única concepción válida de monopolio es que éste «solo puede surgir cuando el Estado impide el acceso libre a una parcela (reservándosela para sí o) concediéndosela a uno o varios privilegiados en detrimento del resto de agentes, que son vedados» (Huerta de Soto, 2009-2020: tema 21.3).

\section{El precio de monopolio y la subproducción}

El argumento del precio de monopolio se basa en la suposición de que hay un "precio competitivo», al que se opone un precio más elevado - el de monopolio - resultado de la acción restrictiva (Rothbard, 2013a: 192). Idéntico argumento se utiliza para prohibir legalmente los cárteles: «un cártel es una organización de empresas independientes que producen bienes similares y que trabajan conjuntamente para elevar los precios y restringir la producción» (Samuelson y Nordhaus, 2006: 184). Sin embargo, la afirmación de que alguien produce una cantidad «demasiado» baja o que el precio fijado es una cantidad «demasiado» alta no está exenta de problemas. La razón de peso es que no hay forma de determinar científicamente la existencia de un "precio competitivo» ni tampoco el de una cantidad de producción considerada objetivamente como «óptima».

Veamos en primer lugar la problemática del concepto de "precio competitivo». Empezaremos diciendo que, en el libre mercado, todos los precios son competitivos. El único precio «no competitivo» es aquél impuesto bajo la violencia o la amenaza de violencia. Aún en el caso supuestamente más «desfavorable» de que exista un único proveedor de un bien en un territorio dado, siempre existen bienes sustitutivos cuyos precios compiten con los del primero. El monopolista no queda a salvo de la influencia de la competencia (Rothbard, 2013a: 178). La posibilidad de restringir la oferta y subir 
el precio para obtener un mayor beneficio nunca está garantizada, es algo que el empresario deberá experimentar mediante ensayo y error, y que dependerá, en última instancia, de la inelasticidad de la curva de demanda. Pero esta forma de buscar la mayor rentabilidad no es exclusiva del monopolista.

También puede suceder que el "precio competitivo» de muchas pequeñas empresas similares sea más elevado que el «precio monopolista» de una gran corporación que obtiene economías de escala. Los economistas neoclásicos pretenden que ninguna empresa «grande» pueda fijar un precio superior al ingreso marginal y olvidan que en las empresas, a medida que disminuye su tamaño, crece la curva de costes marginales; por tanto, las hipótesis de partida quedan modificadas por este hecho. Lo relevante para el consumidor es obtener la mejor relación calidad-precio, según su personal escala de valores, independientemente de que exista uno, varios o muchos competidores.

En segundo lugar, hablemos de la «subproducción». Todos los empresarios, sean grandes o pequeños, actúan de forma especulativa y si alguno detecta que su mercancía puede ser vendida a un precio más alto en el futuro la almacenará con la finalidad de incrementar sus beneficios. Todo empresario siempre procura producir aquella cantidad que le reporta el máximo beneficio. Esto no siempre es posible y, en ocasiones, como sucede en la agricultura, puede haber excedentes de producción. En este caso, si los productos son duraderos el empresario los almacenará para venderlos posteriormente sin descuento pero si son perecederos y/o los costes de almacenamiento exceden al beneficio potencial de la operación, el empresario deberá destruirlos o dejarlos mermar. El empresario nunca planifica producir en exceso para luego destruir el producto sobrante. La destrucción de género, para mantener el precio, significa que el empresario se equivocó en sus estimaciones y ahora debe asumir los costes de ese fallo como un mal menor. Por consiguiente, no hay manera de distinguir la reducción de la oferta de un monopolista de la realizada otro especulador cualquiera. 


\section{Argumentos éticos}

La teoría neoclásica introduce, de forma injusta, una condena moral de las empresas que han alcanzado, por méritos propios, un tamaño considerable. Como afirma Mises (1986: 39):

Los intervencionistas destacan que planean conservar la propiedad privada de los medios de producción, el empresariado y el intercambio en el mercado. Pero agregan que es es perentorio evitar que estas instituciones capitalistas se expandan, causando estragos y explotando injustamente a la mayoría de la gente. Es deber del gobierno restringir mediante órdenes y prohibiciones la codicia de las clases propietarias para que su poder adquisitivo no dañe a las clases más pobres. El capitalismo sin traba alguna, también llamado laissez faire, es un mal.

Pero en el libre mercado el tamaño de cada empresa no queda determinado unilateralmente por el «capital». No es la avaricia de los empresarios sino el egoísmo (rectamente entendido) de los consumidores el que convierte una empresa pequeña en un gigante multinacional. «Una empresa rentable tiende a expandirse, y una que no lo es, tiende a achicarse» (Mises, 1986: 32). A medida que la empresa crece genera economías de escala y puede ofrecer a sus clientes mejores precios que las empresas de menor tamaño. Por tanto, «el monopolio es decidido por el consumidor porque claramente le beneficia» (Bastos, 2005: 31). Se comete una grave injusticia cuando una empresa que ha ido creciendo orgánicamente gracias a su buen hacer es sancionada, troceada o nacionalizada por las autoridades.

El empresario siempre intenta maximizar su beneficio combinando cantidad vendida y precio unitario. Esta conducta es universal y cualquier persona actúa como un empresario que intenta maximizar su utilidad en tanto en cuanto es vendedor de su propio trabajo. Si un empleado recibe una oferta laboral con mayor salario y menor jornada laboral, ceteris paribus, no dudará en aceptarlo. De esta forma, el empleado actúa como un «malvado» monopolista que reduce su producción (tiempo) y aumenta el precio unitario (jornal). Imaginemos un médico veterano que goza de una sólida reputación profesional; el galeno tiene 100 pacientes y ha decidido 
no trabajar los viernes porque quiere disfrutar de más tiempo libre. Como ha reducido un $20 \%$ su jornada laboral, debe reducir también $20 \%$ su clientela y para ello incrementa el precio de cada consulta en idéntico porcentaje. Supongamos que sus planes son acertados y que 80 pacientes aceptan la subida del precio y el resto se traslada a otro proveedor. ¿Actúa el médico de forma inmoral? Al fin y al cabo son los pacientes quienes determinan libremente el grado de inelasticidad de la demanda $(80 \%)$ y no el médico. En este caso, ochenta pacientes valoraban los servicios del médico (al menos) un $20 \%$ más de lo que habitualmente pagaban pero ninguno informó de este extremo al doctor. ¿Acaso estaban antes explotando al médico?.

Si no media violencia ni fraude, cualquier precio acordado entre las partes es ético. De igual modo, los miembros de un cártel acuerdan actuar conjuntamente de forma pacífica y los consumidores pueden siempre oponerse a una subida de precios mediante el boicot comercial.

En economía es frecuente el uso de metáforas y otros términos equívocos que, subrepticiamente, introducen una condena moral sobre las grandes corporaciones. El «imperio» construido por un monopolista como Bill Gates no se parece en nada al imperio de Napoleón, que fue forjado manu militari. Tampoco es cierto que las empresas que poseen una elevada cuota de mercado ejerzan algún tipo de "poder» sobre el mercado. Justo lo contrario, la elevada participación en un mercado es la prueba de haber atendido puntualmente las necesidades de los consumidores. El «poder» es un concepto ajeno al proceso de cooperación social que se produce en el mercado no interferido. El poder es producto de la amenaza o uso de la violencia física. El empresario no puede obligar a los consumidores, ni estos pueden obligar al primero en ningún sentido. La expresión «derechos de los consumidores» puede resultar confusa porque el empresario no tiene ningún deber respecto de los primeros. La «soberanía del consumidor» en modo alguno significa que el empresario deba plegarse a los deseos del primero puesto que «nadie es soberano respecto de los actos o intercambio de cualquier otro» (Rothbard, 2013a: 130). Tampoco el empresario puede «controlar» el precio al cual se realiza el intercambio; el precio puede ser propuesto por una de las partes y es un elemento de infor- 
mación sumamente útil en los procesos comerciales pero el precio debe ser aceptado y nunca es impuesto coactivamente.

III

\section{LOS FALLOS DEL MERCADO}

El argumento neoclásico de los fallos del mercado es consecuencia del auge de la econometría en nuestra Ciencia y de la teoría del equilibrio general del Walras. Las exigencias de la matemática obligaron a los economistas a trabajar con esquemas estrechos de la realidad, fácilmente manejables, hasta tal punto de que no tuvieron más remedio que simplificar las cosas drásticamente. «El ascenso general del rigor científico acabó por producir la sustancia, aunque no el término, de lo que hoy llamamos teoría de la competición pura o perfecta» (Schumpeter, 2012: 1059). Eliminar la competencia del sistema era pues una exigencia ineludible del positivismo económico.

En principio, el modelo de competencia perfecta, entendido como ficción metodológica, no representa inconveniente alguno para el economista, de hecho, «el sistema de investigación típico de la economía es aquél que se basa en construcciones imaginarias» (Mises, 2011a: 288), tal es el caso de la economía de giro uniforme o la sumamente fértil ficción robinsoniana. Tampoco es problemático comparar un modelo imaginario con otro real, siempre y cuando de ambas premisas no se obtenga una conclusión falsa. Creemos que aquí reside el Talón de Aquiles del argumento de los fallos del mercado, en una inferencia lógica inadecuada que ha sido acuñada como la falacia «nirvana» (Demsetz, 1969: 1): «In practice, those who adopt the nirvana viewpoint seek to discover discrepancies between the ideal and the real and if discrepancies are found, they deduce that the real is inefficient». Hecha la comparación entre lo ideal y lo real, resulta irresistible concluir que la realidad es «imperfecta» o que el mercado es «ineficiente» y posee numerosos «fallos». Veamos cómo Samuelson y Nordhaus (2006: 33) introducen el engañoso dilema entre lo ideal y lo real, entre el mercado y el gobierno:

Una economía de mercado ideal es aquella en la que todos los bienes y servicios se intercambian voluntariamente por dinero a los 
precios de mercado. Este sistema extrae el beneficio máximo los recursos existentes en la sociedad sin intervención del Estado. Sin embargo, en el mundo real, ninguna economía se ajusta por completo al mundo idealizado de la mano invisible ${ }^{2}$ que funciona sin dificultades. Más bien, todas las economías de mercado tienen imperfecciones que producen males como una contaminación excesiva, desempleo y extremos de riqueza y pobreza.

Por este motivo, ningún Estado del mundo, por muy conservador que sea, mantiene sus manos alejadas de la economía.

En primer lugar, estos autores ponen en boca de Adam Smith algo que él nunca afirmó, a saber, que la metáfora de la mano invisible fuera referida de algún modo a un mundo ideal. Esta incorreción argumentativa se recoge en el «mandamiento» tercero de la pragma-dialéctica: «attacks on standpoints may not bear on a standpoint that has not actually been put forward by the other party» (Eemeren y Grootendorst, 2004: 191). Cuando Smith (2011: 46) afirma que «no es la benevolencia del carnicero, el cervecero, o el panadero lo que nos procura nuestra cena, sino el cuidado que ponen ellos en su propio beneficio», no parece que esté describiendo un mundo ideal, más bien lo contrario, el escocés describe la realidad sin tapujos y afirma que todo hombre busca su propio interés. Pero lo más relevante de la metáfora smithiana es que pone de relieve la ausencia de conflicto entre los intereses rectamente entendidos del individuo y los intereses de la sociedad. En segundo lugar, Smith (2011: 554) tampoco parecía tener demasiada fe en la labor beatífica del gobierno:

Nunca he visto muchas cosas buenas hechas por los que pretenden actuar en bien del pueblo [... ] El político que pretende dirigir a las personas privadas sobre la forma en que deben invertir sus capitales no sólo se carga a sí mismo con la preocupación más innecesaria sino que asume una autoridad que no debería ser delegada con seguridad en ninguna persona, en ningún consejo o senado, y que en ningún sitio es más peligrosa que cuando está en manos de un hombre tan insensato y presuntuoso como para fantasear que es realmente capaz de ejercerla.

\footnotetext{
${ }^{2}$ Cursiva añadida por el autor.
} 
Por otro lado, los mismos conceptos «perfección» y «eficiencia» resultan confusos cuando son referidos al ámbito de la praxeología. Carece de sentido afirmar que los compradores, vendedores, empresas, o todos en conjunto son «imperfectos» $\mathrm{O}$ «ineficientes»; los individuos tienen conductas concretas que, en todo caso, resultarán acertadas o fallidas según el subjetivo entender de cada actor. Pero aún admitiendo a efectos dialécticos que el mercado fuera «ineficiente» o que tuviera "fallos», es otro non sequitur afirmar que (Samuelson y Nordhaus, 2006: 34): «en todos los casos, las fallas de mercado provocan producción o consumo ineficientes y el Estado puede contribuir significativamente a curar la enfermedad». Incluso si aceptáramos la dudosa existencia de una «infraproducción» del sector privado (en algunos bienes) no se sigue que el gobierno lo haga mejor. Según Block (1983: 3) esta conclusión no es económica, sino normativa: «the contention that government should involve itself with the private economy is a moral conclusion, one that can be reached only if there are ethical arguments in the premises». Los defensores del papel económico del estado no afirman explícitamente que el gobierno sea una institución «nirvana» o que posea una naturaleza más perfecta que la del resto de instituciones, pero al atribuirle la función reparadora de los «fallos» del mercado, tácitamente lo están reconociendo. En todo caso, para ser justos, habría que comparar el mercado y el estado, tal cual son en la realidad (Hummel, 1990: 101): «one must compare the market with the State, not as one wishes the State would behave in some ideal realm, but as it must behave in the real world». Para ver más claramente la inconsistencia del argumento «nirvana» hagamos una analogía: imaginemos que un grupo de científicos sociales construye un modelo del matrimonio "perfecto»: existe una situación de equilibrio, la pareja nunca discute, el amor entre ambos cónyuges es equivalente y constante en todo tiempo y lugar, los esposos tienen conocimiento perfecto del futuro, etc.; posteriormente, comparamos el matrimonio «nirvana» con el matrimonio común y encontramos en el segundo fallos como la infidelidad, la asimetría en el amor, el egoísmo, los divorcios, etc. Y como el matrimonio real es claramente «imperfecto» llegamos a la genial conclusión de que los «fallos» de la institución matrimonial deben ser subsanados por el gobierno. Bajo este esquema no hay institución humana que esté 
a salvo de la intervención correctiva del estado. Sin negar la existencia de problemas como las externalidades, la contaminación ambiental o la sobreexplotación de algunos recursos naturales; no encontramos motivo alguno para pensar dos cosas: a) que existan instituciones calificadas como «imperfectas» o que los problemas económicos, sociales o ambientales puedan ser considerados como «fallos» de alguien; b) que el gobierno sea una institución de naturaleza sobrehumana o que esté mejor capacitada que el mercado para resolver los problemas mencionados.

\section{IV}

\section{LA EFICIENCIA SOCIAL}

Uno de los argumentos más utilizados en economía política es la «eficiencia» social entendida como sinónimo de «eficiencia» económica en la sociedad. Según los economistas neoclásicos, el mercado además de imperfecto es ineficiente. Comencemos elucidando el concepto de eficiencia. Rothbard (2016: 1) la define como «la mejor combinación de medios para fines establecidos». En la literatura empresarial hay un ligero matiz entre eficacia y eficiencia, la primera es el logro de un fin sin realizar un análisis (al menos, detallado) de costes; la eficiencia, en cambio, compara la utilidad obtenida al alcanzar el fin con la desutilidad que supone el coste soportado. Por tanto, eficiencia significa alcanzar un objetivo al «menor» coste (monetario y no monetario). El concepto de eficiencia se emplea para relacionar «fines» pretendidos y «medios» empleados, en el sentido de hacer un balance de utilidades; y habitualmente decimos que algo es eficiente cuando dicha relación es alta comparada con otra que tomamos como referencia. Por ejemplo, afirmamos que la máquina A es más eficiente que la máquina B cuando, por unidad de input consumido, la primera obtiene mayor output que la segunda. También podemos afirmar que $\mathrm{A}$ es más eficiente que B si, a igual rendimiento, A consume menos que B. El concepto de eficiencia en las ciencias físicas y en la técnica es sinónimo de rendimiento. Independientemente del uso que le demos a una máquina podemos afirmar de ella que posee ciertos rendimientos que son mensurables. En cambio, en las ciencias so- 
ciales, la idea de eficiencia se torna difusa pues ésta «sólo existe en relación con ciertos fines y objetivos» (Rizzo, 1979: 71). Y tanto los fines como la utilidad y los costes son subjetivos. En el ámbito de la empresa, a través del cálculo económico, podemos averiguar si determinada decisión ha resultado más o menos eficiente en términos monetarios; la empresa tiene pérdidas o beneficios y el cálculo económico nos sirve de guía aunque sea a posteriori. Pero en el ámbito social, los costes psíquicos adquieren gran relevancia y estos solamente están a disposición del individuo que actúa. Por consiguiente, «no puede haber ningún análisis válido o significativo sobre coste-beneficio en las decisiones legales o políticas, o las instituciones» (Rothbard, 2016: 3).

Una vez más, volvemos a toparnos con el problema del deslizamiento de conceptos del ámbito de las ciencias físicas hacia el ámbito de las ciencias sociales. En este sentido, Rothbard (2016: 1) señala varias cuestiones que comprometen la tesis de la eficiencia en el ámbito social:

a) Primero, al perseguir fines sociales nos damos cuenta que tanto los individuos como los grupos tienen fines diversos $\mathrm{y}$, a menudo, conflictivos entre sí. Por ejemplo, para quien busca incrementar el beneficio, si la máquina A requiere la mitad de operarios que la máquina $\mathrm{B}$, ceteris paribus, sustituir B por A es económicamente «eficiente» pues reduce $50 \%$ el coste del factor trabajo. Para la mitad de operarios que permanece en la empresa usando la nueva maquinaria el cambio también podría ser «eficiente» (o útil), tal vez, el trabajo es ahora menos penoso, o más seguro, o incluso el aumento de la tasa de capitalización incrementa el salario nominal. Para la otra mitad de operarios despedidos y sindicalistas el cambio es «ineficiente» en términos de cantidad de empleos. A medida que nos desplazamos desde el ámbito de la máquina hacia el ámbito de lo humano, el concepto «eficiencia» se va tornando más difuso y preferimos emplear la palabra «utilidad». Creemos que la «eficiencia social» es una secuela del utilitarismo.

b) Segundo, tampoco podemos agregar — sumar y restar- fines, utilidades, costes o eficiencias para poder elegir entre fines sociales alternativos; entre otros factores porque «la economía 
cuantitativa no existe» (Huerta de Soto, 2004: 65). No es posible determinar un óptimo social porque el valor, la utilidad y los costes son conceptos inconmensurables, es decir, no poseen unidades de medida y únicamente residen en la mente del individuo. Volviendo al ejemplo anterior, ¿qué es socialmente más eficiente: la mejora tecnológica de la empresa, el aumento de la producción y el incremento nominal de los salarios del 50\% de operarios o el desempleo temporal del 50\% restante? Cualquier respuesta es necesariamente arbitraria pues todo depende de a quien formulemos la pregunta.

c) Tercero, ni siquiera las acciones individuales pueden ser asumidas como «eficientes». Por ejemplo, mediante la experiencia y la práctica, un operario va incrementando gradualmente su destreza y rendimiento de tal forma que es posible afirmar que el operario $C$ es más «eficiente» hoy que hace un año o que $C$ es menos «eficiente» que el operario D. Pero este último puede tener un mal día y la «eficiencia» puede invertirse. El concepto de eficiencia puede servirnos sólo cuando comparamos máquinas y procesos relativamente simples dentro de un sistema orientado hacia una misma finalidad. Una vez que abordamos el campo complejo e intrincado de los procesos sociales resulta de todo punto estéril establecer juicios sobre la mayor o menor eficiencia de un sistema sobre otro. «La eficiencia es por lo tanto, una quimera» (Rothbard, 2016: 1).

Para alcanzar la mayor utilidad, y dada la problemática apuntada, lo único razonable, económicamente hablando, es permitir que cada individuo pueda expresar lo que subjetivamente considera más «eficiente» $\mathrm{O}$ «útil», en cada circunstancia, momento y lugar, a través del proceso social del mercado (Huerta de Soto, 2012: 55):

En agudo contraste con las diferentes versiones del análisis económico que considera que el mercado se encuentra en un equilibrio aquejado de fallos (neo y post Keynesianos), o carente de ellos por ser pareto-eficiente (Escuela de Chicago), los cultivadores de la Escuela Austriaca consideran que ambas versiones del análisis del equilibrio, a pesar de su oposición ideológica, adolecen de la misma incomprensión sobre el funcionamiento real del 
mercado, entendido como un proceso empresarial de creatividad y coordinación que, por definición, nunca puede alcanzar ningún óptimo de tipo paretiano (Huerta de Soto, 2010), pero que es dinámicamente eficiente (en el sentido de que impulsa la creatividad y la coordinación) siempre que la coacción institucional del Estado (intervencionismo y socialismo) no dificulte el ejercicio de la función empresarial y la libre apropiación de los frutos de su acción creadora (respeto a la propiedad privada en el marco de un estado de derecho con un gobierno de poderes limitados).

Solamente la libertad, en ausencia de coacción y fraude, puede aproximarnos a lo que habitualmente se entiende como «eficiencia o utilidad social». Rothbard (2013b: 10) afirma:

Cuando la gente es libre de actuar, actúa siempre de una forma que cree que maximizará su utilidad [...] Si nos permitimos usar el término «sociedad» para describir el patrón de todos los intercambios individuales, podemos decir que el libre mercado «maximiza» la utilidad social, pues todos ganan en utilidad.

O como dice Huerta de Soto (2004: 57), refiriéndose explícitamente al vínculo entre libre mercado y eficiencia:

Tan sólo éste, y no otro, puede ser el criterio relevante de eficiencia económica. Un sistema será tanto más eficiente conforme más libremente actúe la función empresarial buscando oportunidades de beneficio [...] El fantasmagórico concepto paretiano de eficiencia es inútil e irrelevante, pues ha sido elaborado en el invernadero teórico de la escuela de los economistas del bienestar, y exige para su manejo operativo un entorno estático y de plena información que jamás se da en la vida real.

Para entender mejor todas estas afirmaciones, analicemos un supuesto muy sencillo. Mediante el trasplante de córnea una persona puede recuperar la vista. Si alguien sano decide libremente donar (o vender) una de sus córneas a un ciego ambos salen beneficiados de la donación (o intercambio) y nadie ha sido perjudicado; en este caso podríamos afirmar que la sociedad ha mejorado en su conjunto o que el trasplante ha sido Pareto-eficiente. Supongamos ahora que el gobierno, mediante un estudio de coste-beneficio social, determina 
que es socialmente más eficiente que haya dos personas tuertas frente a otras dos, una ciega y otra sana (visión binocular); ¿debería extirpar forzosamente una córnea al sano para dársela al ciego? Si entendemos por sociedad el conjunto de todos los individuos de una comunidad - y aquí la escala no es relevante- no es posible afirmar que la utilidad social aumenta cuando uno solo de sus miembros ha sido lesionado. Por tanto, resulta dudosa la afirmación de que pueda alcanzarse algún tipo de eficiencia social oponiéndose a los legítimos fines de los integrantes de la sociedad - los individuos-y utilizando para ello la compulsión institucional.

\section{$\mathrm{V}$ \\ EXTERNALIDADES}

Según Mises (2011a: 773) existen situaciones de mercado donde el propietario no disfruta ni soporta todos los efectos de su propiedad, surgiendo los «costes y economías externos», también denominados externalidades o «costes sociales» (Alfaro et al., 2007: 13). En economía, las externalidades han sido estudiadas dentro de los procesos productivos pero debemos aclarar que una externalidad es un fenómeno praxeológico que no queda restringido al ámbito económico. Las externalidades se aprecian en la producción, en el consumo y en las actividades humanas en general. Para una persona que no puede dormir a causa del ruido, no hay diferencia si éste proviene de la producción de ocio de una discoteca o del consumo de ocio de la fiesta de un vecino. La contaminación de una ciudad es provocada simultáneamente por las emisiones de una industria o por los humos procedentes de la calefacción de los hogares. Tampoco hay diferencia entre el $\mathrm{CO}^{2}$ emitido por un vehículo usado como factor de producción y otro usado como bien de consumo. Las externalidades existen, en mayor o menor medida, en casi todas las actividades humanas y la única persona inmune sería un náufrago, sólo en su isla. Como afirma Block (1983: 2): «for all socalled private goods affect second or third parties in some way» («todos los llamados bienes privados afectan de alguna manera a segundas y terceras partes»). Si unos conductores pagan la autopista de peaje otros conductores se benefician gratuitamente de un 
tráfico menos congestionado en las carreteras públicas. Cuando alguien compra o alquila una plaza de garaje otros conductores disponen de más espacio para aparcar en la vía pública. Y los que pagan sanidad y educación privadas descongestionan los hospitales y colegios públicos.

En segundo lugar, la externalidad es un concepto subjetivo. Un mismo efecto puede ser visto, por diferentes sujetos, como una externalidad positiva o negativa. Por ejemplo, la instalación de un tranvía eléctrico en una ciudad reduce la contaminación a lo largo de su trayecto pero aumenta las emisiones de la central térmica (que abastece en última instancia a la máquina). Unos reciben menos contaminación a expensas de otros. Es muy posible que se produzca una reducción neta de las emisiones si las de la central son menores que las equivalentes para mover una flota de autobuses; pero no cabe duda de que se producen externalidades contrarias en diferentes individuos. De igual modo, si el ayuntamiento instala una parada de taxi en cierta calle, los vecinos disponen ahora de menos espacio público para aparcar, en cambio, el panadero situado en las inmediaciones de la parada verá incrementadas sus ventas.

En tercer lugar, la externalidad es un fenómeno heterogéneo en su naturaleza e intensidad y puede producir, simultáneamente, efectos contrarios. Nuestro panadero ha incrementado sus ventas, sin embargo, no todo son ventajas: ahora debe aparcar algo más lejos y los clientes del taxi arrojan las colillas en la puerta de su negocio. Sobre las externalidades positivas hablaremos en el apartado VII: El free rider. Ahora nos ocuparemos de las externalidades negativas.

\section{1. ¿Qué externalidades requieren intervención estatal?}

Según los economistas neoclásicos una externalidad constituye un «fallo de mercado» que debe subsanarse con la intervención del gobierno. Puesto que hay tantas externalidades, en tipo, intensidad y sentido (positivo y negativo), el primer problema al que se enfrenta un órgano planificador es determinar cuáles de las externalidades negativas requieren intervención pública. Existe un amplio consen- 
so de que la contaminación de ríos, mares y otros espacios públicos requiere adoptar políticas que reduzcan sus efectos nocivos. Esto parece necesario en tanto no se disponga de una asignación más precisa de los derechos de propiedad. Un mayor incremento de los espacios bajo titularidad privada reduce la necesidad de intervención pública pues la vigilancia y control de los daños externos correría a cargo de los propietarios. Sin embargo, la intervención para reducir las externalidades negativas se ha ido extendiendo progresivamente hacia otros campos de actividad económica cuya justificación es más que discutible. El gobierno impone tributos especiales sobre el tabaco o el alcohol porque producen externalidades en forma de mayor gasto sanitario, por ejemplo. Pero la propia externalidad que se pretende combatir es fruto de una intervención previa del gobierno: la estatización de la sanidad. En el libre mercado los mayores costes económicos derivados de ser fumador o bebedor se internalizan en cada cliente mediante el pago de mayores primas en los seguros de salud. Esto es visible en los seguros de hogar o automóvil: a medida que los clientes tienen más siniestros la prima del seguro va aumentando. El mercado, de forma espontánea, encuentra mecanismos capaces de reducir las externalidades mientras que el estado, como veremos, es un gran generador de las mismas. Además, la aceptación social de que el gobierno es un ente benefactor da pie a la continua extensión del campo de la intervención, tanto horizontalmente, con nuevos impuestos, como verticalmente, aumentando los tipos marginales que gravan las sustancias «peligrosas». De este modo, las gaseosas pueden ser gravadas porque su alto contenido en azúcar incrementa el riesgo de sufrir diabetes, y la bollería industrial porque su alto contenido en grasa animal incrementa el colesterol y el riesgo de sufrir enfermedades cardiovasculares. Simultáneamente, por contradictorio que parezca, el gobierno subsidia a los productores de remolacha azucarera o de ganado porcino porque, supuestamente, el sector primario es productor de externalidades positivas. De esta forma, productos que poseen las mismas sustancias son penalizados o subsidiados según criterios altamente discrecionales. El argumento de las externalidades, con frecuencia, es usado instrumentalmente por el gobierno para alcanzar sus fines particulares y aquellos de los grupos de interés. 


\section{2. ¿Es inmune el gobierno a las externalidades?}

Los economistas neoclásicos culpan al libre mercado de producir externalidades negativas pero cabría preguntarse qué tal se comporta el sector público en este campo. Nuestra hipótesis es que el gobierno, lejos de ser un solucionador de problemas, es un causante de externalidades negativas:

a) El gobierno es un monopolio fiscal que extrae violentamente la riqueza producida por los individuos productivos. La mayoría de la población considera el impuesto como una desutilidad.

b) El gobierno redistribuye la riqueza y en esta función consume una parte significativa de los recursos. El gobierno, forzosamente, debe repartir menos bienes de los que extrae.

c) El gobierno tiene el monopolio de la violencia y puede ejercerla sobre la población propia y sobre otros pueblos, haciendo la guerra.

d) El gobierno tiene el monopolio del dinero y puede causar inflación.

f) El gobierno tiene el monopolio legal y puede restringir la libertad de los individuos mediante normas y regulaciones arbitrarias (intervencionismo).

g) El gobierno puede imponer a toda la población una moral heterónoma y sancionar a personas que cometen «crímenes sin víctimas».

Evidentemente, para algunos grupos la acción del gobierno es favorable. Para todos aquellos consumidores netos de impuestos - políticos y funcionarios- la existencia del estado es una gran externalidad positiva. Los economistas neoclásicos consideran que toda la sociedad en su conjunto sale beneficiada cuando el estado fomenta la equidad mediante la redistribución de la riqueza (Samuelson, 2006: 34). Esto último no es tan evidente y prueba de ello es la resistencia secular al pago de impuestos y al cumplimiento de determinadas leyes. En la medida en que un gobierno recauda una mayor cantidad de dinero puede incrementar su esfera de actuación y su poder: «un gobierno es tan fuerte como lo son sus ingresos» (Chodorov, 2002: vii). Y allí donde el mercado 
no producía externalidades el gobierno las crea. Los costes de educación o sanidad, en el libre mercado, quedan internalizados en los consumidores del servicio; sin embargo, el gobierno confisca a aquellos que no tienen hijos para costear las guarderías, colegios y universidades; confisca a las personas sanas para sufragar la atención de las enfermas; confisca a los que trabajan para pagar el desempleo o las pensiones; y así sucesivamente. El gobierno, de oficio o presionado por grupos de interés, crea falsos bienes públicos y nuevas externalidades. Esto opina Hummel (1990: 102) al respecto:

Esto hace posible la organización de grupos para conseguir que el Estado provea falsos bienes públicos, bienes y servicios que de hecho cuesta mucho más de lo que los beneficiarios estarían dispuestos a pagar inclusive si la exclusión fuese posible y no pudiera haber free-riders. De esta manera, el Estado genera externalidades, y de esas que son negativas. En lugar de superar el problema del free-rider, el Estado beneficia a los gorrones, quienes reciben bienes públicos falsos a expensas de los contribuyentes.

Existe un doble rasero para medir las externalidades: las que produce el mercado son nocivas para la sociedad y las producidas por el intervencionismo son beneficiosas. Cualquier acción gubernamental, sea fiscal o de otro tipo, ocasiona sistemáticamente una doble externalidad: positiva para unos y negativa para otros. Esto es un hecho praxeológico, independientemente de su aceptabilidad social, jurídica o ética. El gobierno transfiere coactivamente recursos económicos de unas personas hacia otras y genera tantos tipos distintos de externalidades, y en tantas direcciones, que no podemos saber con precisión quienes resultan, de forma integral, perjudicados o beneficiados. Podemos identificar algunas externalidades negativas del gobierno:

a) La guerra es posiblemente su mayor externalidad negativa. Como decía Randolph Bourne (2013: 8) cuando EEUU se incorporó a la Gran Guerra: «la guerra es la salud del Estado. [...] El Estado está íntimamente conectado a la guerra, porque el Estado es la organización de la comunidad colectiva actuando de forma política contra un grupo rival, haciendo la guerra». 
b) En tiempo de paz, la gran externalidad del gobierno es la confiscación que reduce el nivel de vida de los ciudadanos.

c) La inflación es otra gran externalidad que causa ciclos económicos y reduce el poder adquisitivo de la población.

d) En general, las externalidades del estado son proporcionales al grado de monopolización que ejerce en los distintos ámbitos económicos: defensa, justicia, seguridad, creación de leyes, moneda, educación, sanidad, urbanismo, transporte, etc.

VI

TEORÍA DE LOS BIENES PUBLICOS

Según Samuelson (2006: 34): «Los gobiernos aumentan la eficiencia cuando promueven la competencia, reducen externalidades como la contaminación y proveen bienes públicos». En este apartado trataremos la teoría neoclásica de los bienes públicos, que analiza los bienes según los criterios de excluibilidad y rivalidad en el consumo. Tras este análisis, aparecen cuatro categorías: bienes públicos, bienes privados, recursos comunes y monopolio natural, que presentan una serie de distinciones según los criterios señalados.

\section{Tipos de bienes}

\section{a) Bienes públicos}

«Los bienes públicos son bienes que todos pueden disfrutar y que es imposible impedir que alguien los disfrute» (Samuelson \& Nordhaus, 2006: 35). Dicho de forma más técnica, son bienes cuyo consumo satisface dos criterios: a) Excluibilidad: no es posible excluir a nadie del consumo de ese determinado bien, por ejemplo, no podemos impedir que un peatón o un vehículo circulen por la vía pública; b) Rivalidad: no existe rivalidad en el consumo del bien. El consumo de una persona no excluye ni reduce el consumo de ese mismo bien por parte de otros consumidores adicionales. El aumento marginal del número de consumidores no aumenta el coste 
marginal de producción del bien en cuestión, o dicho de otro modo, para el productor, el coste marginal de añadir un consumidor más es cero.

\section{b) Bienes privados}

La mayoría de bienes económicos ${ }^{3}$ de naturaleza física (productos y factores de producción) son privados porque existe la posibilidad de excluir del consumo a aquellos que no quieren o no pueden pagar por su adquisición ${ }^{4}$, de otra parte, existe rivalidad en su consumo. Por ejemplo, si una persona ingiere un vaso de leche, esa misma cantidad de alimento no puede ser ingerido por otra persona. Es preciso advertir que la teoría de los bienes públicos soslaya satisfactoriamente la problemática cuestión de la «esencialidad» de los bienes. Recordemos que muchos autores afirman que la defensa nacional, la seguridad o la justicia son bienes públicos porque son «esenciales» para la sociedad. Alguien podría decir, en cambio, que el agua o los alimentos son todavía más esenciales que los anteriores. Los alimentos son bienes privados, no porque sean más o menos «esenciales» que otros sino porque su consumo satisface los criterios de exclusión y rivalidad.

\section{c) Recursos comunes}

Son bienes donde hay rivalidad en el consumo pero no es posible excluir a nadie. El caso de la vía pública es paradigmático: existe una gran rivalidad por encontrar aparcamiento pero no es posible excluir a los conductores de usar las calles. Sin embargo, las propias autoridades han ideado fórmulas de exclusión como las tarjetas de aparcamiento para discapacitados o residentes, las zonas de carga y descarga, la limitación del tiempo de aparcamiento o el uso

\footnotetext{
${ }^{3}$ Un bien no escaso, como el aire o el agua del océano, no es un bien económico.

${ }^{4}$ Una de las funciones del sistema de precios es asignar los bienes a los compradores. La otra es orientar a los empresarios sobre qué bienes deben ser producidos y cuáles no.
} 
por pago (parquímetros). Otras medidas, como que los vehículos con matriculas pares (o impares) circulen por la ciudad en días alternos no suelen ser efectivas y enojan a los ciudadanos. La intervención gubernamental, en ocasiones, agrava el problema por el lado de la oferta limitando el espacio disponible (la ordenación urbanística puede dificultar la construcción de aparcamientos privados) o prohibiendo el uso compartido del taxi, las moto-taxi o el trabajo de taxistas ocasionales (Uber).

\section{d) Monopolio natural}

Cuando hay un monopolio natural es posible excluir al consumidor que no paga por el servicio pero los productores, una vez hechas las infraestructuras básicas, pueden abastecer a consumidores adicionales con un aumento despreciable de los costes de producción. Las empresas que suministran agua y energía constituyen ejemplos de monopolios naturales.

\section{Criterios de excluibilidad y rivalidad}

Intentaremos demostrar, utilizando la propia teoría de los bienes públicos, que no existe una clara dicotomía entre bienes públicos y privados, todos los bienes son más o menos públicos o privados y constantemente cambian al respecto en función de las valoraciones de la gente (Hoppe, 2013: 84).

En primer lugar, la no excluibilidad de los bienes públicos puede ser cuestionada. La seguridad privada es un buen ejemplo: las alarmas antirrobo sólo se instalan en las viviendas de los clientes y la patrulla policial solo recorre las urbanizaciones o comunidades que pagan por el servicio. La excluibilidad es un concepto gradual y siempre existirán externalidades positivas y free riders, esto es inevitable. Es muy probable que el vecino que no ha contratado seguridad se beneficie indirectamente de su vecino que sí la ha contratado, esto será analizado en el último apartado dedicado al free rider. Por otro lado, la no excluibilidad es un criterio dinámico y cambiante, y a medida que progresa la tecnología surgen nuevas 
posibilidades de excluir del servicio a quien no paga; un ejemplo es la TV vía satélite y por cable.

En segundo lugar, todos los bienes públicos son escasos y siempre existe, en mayor o menor medida, algún tipo de rivalidad en su consumo. La defensa nacional es el paradigma de bien público pero las tropas militares no pueden defender simultáneamente a toda la población y, en caso de conflicto, el mando militar debe priorizar su empleo en los lugares adecuados y momentos oportunos. Idéntico problema se plantea con la intervención de unidades policiales o de protección civil: si una patrulla de policía o una unidad de bomberos acude a una emergencia no estará disponible para dar servicio a otra emergencia que suceda al mismo tiempo y en otro lugar. En la administración de justicia ocurre otro tanto, los jueces no pueden atender tantos casos como se plantean y si atienden unos forzosamente deben posponer otros. Cualquier lista de espera, sea en sanidad o en justicia, es un claro indicador de que existe rivalidad en el consumo.

En tercer lugar, el propio gobierno que apoya la teoría de los economistas neoclásicos, actúa de forma contradictoria. El estado provee muchos bienes que son claramente privados si nos atenemos a los criterios de excluibilidad y rivalidad: sanidad, educación, asistencia social, ferrocarriles, correos, etc.; todos ellos son sectores intervenidos que pueden ser provistos exclusivamente a quien paga por ellos y donde existe rivalidad en el consumo. De hecho, en el pasado todos los servicios que hoy consideramos públicos fueron producidos de forma privada, incluidos los de seguridad y justicia. En España tenemos el Tribunal de las Aguas, una institución medieval que todavía hoy imparte justicia privada en las Comunidades de Regantes de la Vega de Valencia. Pero también existen otros tribunales privados en los ámbitos religioso, mercantil y deportivo.

En resumen, la teoría de los bienes públicos (Hoppe, 2013: 83\%) «es un razonamiento erróneo, ostentoso, montado en contradicciones internas, incongruencias, apelando a interpretaciones basadas en prejuicios y creencias populares asumidas, pero sin mérito científico alguno». 


\section{EL FREE RIDER O GORRÓN}

Praxeológicamente, podemos definir al free rider como el consumidor de bienes procedentes de economías externas. El hecho de que el productor de cierto tipo de bienes no pueda evitar que algunos consumidores se beneficien sin pagar es una circunstancia propia de la economía de libre mercado, si bien esta circunstancia queda fuera del campo de la cataláctica. En el lenguaje coloquial el free rider es un «aprovechado» del sistema cuya conducta ocasiona un perjuicio a la sociedad. Si el productor del bien anticipa que algunos (o muchos) consumidores podrán eludir el pago, tal vez, se cuestione producirlo. Según Mises (2011a: 777) caben dos posibilidades:

1. El interesado estima tan grande su ganancia personal que está dispuesto a soportar íntegramente los costes.

2. El coste resulta tan elevado que ninguno de los potenciales beneficiarios está dispuesto soportarlo integralmente por separado y la obra únicamente puede ejecutarse si un número suficiente de personas aúna sus esfuerzos.

Los economistas neoclásicos consideran que la existencia de economías externas y free riders constituye un «fallo» del mercado pues en éste, se producirá una menor cantidad de bienes de lo que sería socialmente deseable. La solución, una vez más, pasaría por la producción estatal de cierto tipo de bienes donde el free rider hace su aparición. Para ello, el gobierno «puede contratar a un equipo de economistas e ingenieros, a fin de que realicen un estudio llamado análisis coste-beneficio, cuyo objetivo es estimar los costes y los beneficios totales que tendría el proyecto para la sociedad en su conjunto» (Mankiw, 2007: 161). A grandes rasgos, hemos descrito el free rider y cómo su existencia es vista como un fallo de mercado que justificaría la intervención gubernamental. Nuestro objetivo en esta sección es criticar este razonamiento y tratar de justificar cuatro hipótesis:

a) El free rider se comporta de una forma económica, jurídica y ética. 
b) Desde el subjetivismo, identificar un free rider puede resultar problemático.

c) El free rider no representa un problema significativo para los productores de economías externas ni para la sociedad en su conjunto.

d) El mercado desarrolla continuamente formas para excluir del consumo a aquellos que no desean pagar por ciertos bienes económicos.

\section{Comportamiento del free rider}

En primer lugar, el comportamiento del free rider es económico. El oportunismo está inserto en la naturaleza de todos los seres vivos y es un hecho constatable que el ser humano, si es capaz de detectar una oportunidad, intentará aprovecharla. Entendemos por oportunidad una situación que, debidamente gestionada, puede proporcionar al agente un beneficio alto en relación con el coste soportado. Este tipo de conducta es propio de la función empresarial: «en un sentido general o amplio la función empresarial coincide con la acción humana misma» (Huerta de Soto, 2010a: 41). Por tanto, disfrutar de los beneficios de una situación preexistente o sobrevenida forma parte de la racionalidad económica. También puede suceder que el beneficiario de una externalidad no sea consciente de tal hecho, en este caso, el beneficio no procede de una conducta económica deliberada e intencional del free rider.

En segundo lugar, la conducta del free rider es jurídicamente correcta pues no viola derecho alguno, en especial la propiedad del productor y de los consumidores que pagan por los bienes. El beneficio del free rider no procede de una relación contractual, explicita o tácita, que obligue al pago de la utilidad recibida (Block, 1983: 9): «but certainly he has not asked for these benefits, and in no case can he be alleged that he has contracted for them». El «gorrón» o «aprovechado», al contrario que el criminal, no obtiene un beneficio ejerciendo el fraude o la violencia con evidente perjuicio de la parte agredida. El free rider tampoco merma los derechos de propiedad del consumidor que ha pagado un precio de mercado. Por tanto, el apelativo de «parásito» resulta inadecuado para describir 
al free rider pues un parásito se alimenta a expensas de su huésped mientras que el disfrute del gorrón no se produce a expensas de nadie. Recordemos, estamos hablando de bienes donde no existe una rivalidad apreciable en el consumo del bien.

Existen otra situaciones, como en el pago de impuestos, donde una persona puede ser vista como free rider en el sentido de demostrar una conducta antisocial. Aquí hay dos figuras, la elusión fiscal y la evasión fiscal; la primera se refiere a un comportamiento acorde a derecho y el contribuyente utiliza los resquicios de la ley para pagar menos impuestos; en cambio, la evasión fiscal es una violación premeditada de una norma jurídica. Aprovecharse de los loopholes o vacíos existentes en la legislación es una actividad muy frecuente en los ámbitos político, fiscal y judicial. Sin embargo, aprovecharse económicamente del mayor conocimiento técnico de las leyes no es gratis, tal vez, el contribuyente debe contratar los servicios de un asesor fiscal o debe pasar muchas horas estudiando la intrincada legislación tributaria.

En tercer lugar, el comportamiento del free rider es ético siempre y cuando no medie fraude o violencia sobre terceros. Algunos autores introducen subrepticiamente reparos morales y afirman, por ejemplo, que el beneficio del free rider es «inmerecido», como si tal cosa pudiera ser considerado un criterio de justicia. También podría considerarse «inmerecido» adquirir riqueza mediante la donación o sucesión, o ser agraciado por la naturaleza con una mayor belleza, vigor físico o inteligencia. La lotería puede ser vista como una externalidad ocasionada por el azar, de hecho, unos pocos free riders se enriquecen a expensas de muchos sin esfuerzo alguno y sin haberlo «merecido». Sin embargo, nadie aprecia como «fallo» de mercado que alguien se haga millonario a expensas de la mayoría de jugadores. El mero hecho de participar en el juego implica consentimiento y validez ética de la externalidad. Mankiw (2007: 159) equipara al free rider con un «parásito» y lo define como «la persona que recibe el beneficio de un bien pero evita pagarlo»; pero alguien podría afirmar que es el productor de la externalidad quien actúa negligentemente al no saber excluir a los que no pagan o no monetizar adecuadamente su servicio. Esto último se observa con la «reventa» de entradas en el fútbol (y otros eventos donde el precio figura en el ticket). Los clubes tienen 
libertad para fijar dinámicamente el precio tal y como sucede con el pescado en la lonja, las acciones en bolsa o más recientemente, la venta de los billetes aéreos por Internet; pero los clubes deportivos prefieren mantener el precio habitual de las entradas para no enfadar a sus clientes habituales. Y como la demanda es muy superior a la oferta, el reparto de entradas mediante sorteo o por antigüedad en el club, es un premio a los abonados de temporada, es un bono económico que sirve a la fidelización de sus clientes. Una vez que la entrada está en poder del socio (o de quien ha hecho más tiempo la cola en la taquilla), cada propietario es libre de disfrutar la final de la Champions League o de monetizar, mediante la reventa, el bono económico otorgado por el Club. La reventa, no sólo es una actividad éticamente impecable, sino que además proporciona ventajas económicas a revendedores y compradores (Block, 2012: 36\%). Los primeros valoran más el beneficio de la reventa que el tiempo que deben pasar haciendo cola y los segundos valoran más el tiempo que se ahorran haciendo cola que el dinero pagado por la entrada. Volviendo al free rider, en cualquier caso, evitar o eludir pagar algo que no ha sido solicitado ni contratado no puede significar una condena moral. Si al productor de una externalidad no le importa que otros resulten beneficiados por su trabajo solo cabe alegrarnos de su generosidad y los beneficiarios no pueden ser culpados de este hecho. ¿Acaso los cientos de millones de usuarios de Wikipedia son todos unos parásitos inmorales que «evitan» pagar el trabajo de los miles de voluntarios que redactan y corrigen los contenidos? Otro indicio sobre la conducta moral del free rider es que se produce con transparencia y publicidad; el gorrón no oculta su condición y este hecho, tal vez, implica un cierto grado de moralidad en la acción. Por último, aludimos a un principio general analizado extensamente por Kirzner (1995) que reconcilia la utilidad obtenida en el libre mercado con la moralidad; "de manera que ambas consideraciones, las relativas a los principios morales y las de eficiencia económica, lejos de oponerse, se refuerzan y respaldan mutuamente» (Huerta de Soto en Kirzner, 1995: 24). 


\section{2. ¿Es posible identificar al free rider?}

Otra cuestión ampliamente soslayada por la mayoría de economistas es la referida a la identificación de los beneficiarios de las economías externas. Puesto que el valor es subjetivo ¿cómo podemos saber si alguien resulta beneficiado o perjudicado de una externalidad? Veamos algunos casos para ilustrar este problema. Analicemos un primer ejemplo donde existe un intercambio: se trata del hombre adinerado, entrado en años, que inicia una relación sentimental con una bella y joven señorita; es frecuente afirmar que ella se «aprovecha» económicamente de él pero no es menos cierto que él también se «aprovecha» psíquicamente de ella. Un praxeólogo diría que, mientras la relación sea consentida, el hecho que sigan juntos revela que ambos se benefician de la relación. Tampoco hay forma de saber quien de los dos obtiene más valor del intercambio porque la utilidad es inconmensurable y, por consiguiente, la comparación intersubjetiva es imposible. Este primer ejemplo nos sirve para poner de manifiesto que la utilidad obtenida siempre es psíquica y que los factores económicos forman parte de la primera.

En las externalidades no hay intercambio, la relación no es cataláctica, una parte activa provoca un efecto positivo o negativo sobre otra parte pasiva que resulta supuestamente beneficiada o perjudicada; pero distinguir esto último no es tan sencillo. Veamos un segundo ejemplo: supongamos un estadio de fútbol que es colindante con un edificio de gran altura. Los vecinos de los pisos más altos, desde el balcón, pueden disfrutar de los partidos sin pagar la entrada; alguien podría afirmar que estos propietarios son beneficiarios de una externalidad positiva pero, de antemano, desconocemos si a esas personas les agrada o no el fútbol; el vecino del $9^{\circ} \mathrm{A}$, que es un gran seguidor del equipo local, puede sentirse agraciado mientras que el vecino del $9^{\circ} \mathrm{B}$ se siente desgraciado porque el ruido del estadio le impide dormir la siesta algunos domingos. Pero el vecino del $9^{\circ} \mathrm{A}$, tal vez, no vive solo y su familia puede ver con desagrado cómo los días que hay un encuentro deportivo la casa se llena con otros free riders ocasionales que han sido invitados por el anfitrión. Los vecinos del $8^{\circ}$ y $7^{\circ}$ piso, solo tienen vistas, respectivamente, del $70 \%$ y $40 \%$ del terreno de juego y para ellos el beneficio de la externalidad positiva es parcial. Los vecinos del $6^{\circ}$ piso e 
inferiores no ven absolutamente nada y sufren todos los inconvenientes del partido: ruido, suciedad en las calles y escasez de aparcamiento durante varias horas, a excepción de los vecinos del $2^{\circ} \mathrm{A}$ y $3^{\circ} \mathrm{B}$ que pasan siempre los fines de semana fuera de casa; para ellos, el evento deportivo tiene un efecto neutro. La vecina del $5^{\circ} \mathrm{A}$ también sufre todos los inconvenientes antes mencionados pero como su yerno es socio del club y tiene un abono de temporada, los días de partido tiene la fortuna de que su hija y sus dos nietos pasan la tarde con ella en su casa. El vecino del $4^{\circ} \mathrm{A}$ tiene pérdida auditiva y el ruido del estadio no le importuna. El vecino del $4^{\circ} \mathrm{B}$ tiene una moto y no sufre los problemas de aparcamiento en la zona. Por último, el dueño del bar situado en los bajos del edificio tampoco puede ver el partido pero está feliz de hacer una buena recaudación los días de fútbol.

\section{3. ¿Es el free rider un problema significativo?}

La teoría de los bienes públicos afirma que la existencia de externalidades positivas haría que determinados servicios en el libre mercado se produjeran de manera «insuficiente» en cantidad y/o calidad, o que dejaran de producirse. Sin embargo, una mera observación de la realidad cotidiana puede cuestionar la, a nuestro juicio, magnificada importancia que otorga la teoría samuelsoniana al free rider. En primer lugar, las externalidades positivas no constituyen un obstáculo para la producción bienes económicos. La construcción de sendas, veredas, caminos, puentes, escuelas, hospitales, plazas e iglesias, en tiempos relativamente recientes, era realizada o financiada privadamente por los habitantes del territorio sin importarles que otras personas disfrutaran de esas infraestructuras. Otro ejemplo claro lo vemos en las fiestas populares, que eran costeadas íntegramente por los vecinos antes de que los ayuntamientos comenzaran a dirigirlas, organizarlas y subvencionar a los participantes. Sin embargo, todavía hoy quedan restos visibles de lo que antaño era una actividad pública en su consumo pero privada en su producción. Durante la celebración de muchas fiestas patronales en España, los vecinos a nivel de pueblo, barrio e incluso 
calle $^{5}$ sufragan eventos tales como fuegos artificiales, bandas de música, cornetas y tambores; ornamentaciones florales, cantantes y artistas, etc.; en algunos sitios son las empresas locales las que corren con los gastos y en otros la financiación es mixta: privada y pública. Uno o varios recaudadores privados van, casa por casa, pidiendo aportaciones económicas para sufragar los gastos de las fiestas. Cada vecino aporta de su peculio la cantidad que quiere (o puede) sin que exista hostilidad hacia los que pagan menos o no han pagado nada. La existencia de free riders no es considerado un problema, ni por los recaudadores privados, ni por el resto de vecinos que aporta trabajo o dinero; en realidad, nadie excepto el recaudador, sabe quiénes y cuánto han pagado. En realidad, no sabemos con precisión quien puede ser free rider: un donante de $5 €$ podría ser considerado free rider por quien haya donado $10 €$ y éste, a su vez, por quien haya donado $20 €$. Aquí podemos observar que existe un continuo o gradación a la hora de calificar al gorrón. Por concretar un poco más, y ahora citamos un caso real, en Santa Cruz de La Palma los vecinos del barrio de La (Virgen de la) Luz hacen aportaciones para pagar los fuegos artificiales, una parte se paga entre todos para la traca final y otra parte la paga los vecinos de cada calle para sus fuegos particulares. Aún siendo voluntario el pago para todos, cuando los vecinos pagan exclusivamente por los fuegos artificiales de su calle (candelas y fuentes sobre el asfalto) se produce, en cierta medida, un tipo de exclusión: si alguien quiere ver los fuegos de otra calle debe desplazarse conforme avanza la procesión religiosa. La tradición de muchos pueblos de España es que los vecinos de cada calle y de cada barrio compiten para que sus eventos y creaciones sean más atractivos que los de sus vecinos. Esta evidencia empírica, constatable actualmente por cualquier economista o sociólogo, refuta la tesis según la cual el libre mercado no producirá un espectáculo pirotécnico debido a la existencia de free riders (Mankiw, 2007: 159). Otro ejemplo donde la existencia de free riders no impide la producción de fuegos artificiales se observa con ocasión

\footnotetext{
${ }^{5}$ Esto viene sucediendo hace decenios en Santa Cruz de La Palma y en otras ciudades de Canarias.
} 
de fiestas privadas; por ejemplo, a los que celebran una boda o un cumpleaños en un recinto privado (y acotado) no parece importarles demasiado que los espectadores situados en el exterior de la propiedad disfruten igualmente del espectáculo.

En segundo lugar, volvemos aquí a refutar la falacia de la «eficiencia social». Los economistas neoclásicos afirman que, debido al efecto free rider, los fuegos artificiales (por seguir con el mismo ejemplo) no se producirán en un espacio público o que, en todo caso, se quemará menos cantidad de pólvora de la cantidad «socialmente deseable». «Los recursos en la sociedad son limitados y pueden usarse para innumerables fines alternativos. ¿Con qué estándar se determina que las cantidades para ciertos usos son «excesivas» o «insuficientes»? (Rothbard, 2013b: 26\%). El mismo concepto de deseabilidad social resulta abstruso: ¿es acaso posible conocer los deseos de la gente? y aún dándolos por sabidos, ¿acaso se puede sumar y restar la deseabilidad? Tal vez, el consistorio decida gastar más dinero de la cantidad calculada misteriosamente por el economista social y, en todo caso, lo más probable que ocurra es un «despilfarro social» pues los que autorizan el gasto disparan (nunca mejor dicho) con "pólvora de rey». Tampoco hay forma de hacer un balance de las externalidades porque es imposible computar el pago y consumo de los servicios públicos. Un caso cotidiano se observa cuando una persona reside en un municipio pero trabaja en otro; según el punto de vista que elijamos, la externalidad puede ser considerada positiva o negativa. El gobierno español considera free riders a quienes trabajan en Gibraltar pero residen en Algeciras porque disfrutan de los servicios públicos españoles mientras que su impuesto sobre la renta se queda en el Peñón. Pero los alcaldes de los siete municipios que forman el Campo de Gibraltar no opinan los mismo, al contrario, consideran a esas mismas personas como cuasi turistas que pagan impuestos ${ }^{6}$ y $\operatorname{tasas}^{7}$ municipales y realizan gran parte de sus compras dentro del municipio. Según se mire, los llanitos residentes en España pueden ser considerados, simultáneamente, como causantes de externalidades negativas y positivas.

\footnotetext{
${ }^{6}$ Impuesto de bienes inmuebles y circulación de vehículos.

7 Tasa de residuos sólidos, vado, etc.
} 


\section{Sobre la propiedad intelectual}

Las reclamaciones sobre la propiedad intelectual no es algo reciente. En su libro ¿qué es la propiedad?, Proudhon (2005: 77) relata cómo los portugueses en el S. XVI deseaban convertir un «descubrimiento» geográfico en un título de propiedad:

Habiendo descubierto los portugueses el paso a las Indias por el Cabo de Buena Esperanza, pretendieron que sólo a ellos correspondía la propiedad del itinerario; y Grotius, consultado por esta cuestión por los holandeses, que se negaban a reconocer tal derecho, escribió expresamente su tratado De mari libero, para probar que el mar no puede ser objeto de apropiación.

Uno de los ámbitos donde es más evidente la presencia del free rider es el de la propiedad intelectual. Según Mises (2011a: 780), estamos ante «el caso extremo de economías externas». La opinión mayoritaria de políticos, economistas, juristas, creadores, artistas y productores es que el Derecho debe proteger las creaciones intelectuales de la misma forma que se protege la propiedad física. Autores como Galambos, Schulman y Rand justifican la protección legal de las creaciones de la mente desde una óptica iusnaturalista (Kinsella, 2008: 16). Los economistas neoclásicos apelan a razones de utilidad y afirman que, sin la debida intervención del gobierno, el efecto free rider supondría una notable pérdida de «eficiencia» social. En ausencia de leyes sobre patentes y derechos de autor la producción de inventos industriales y creaciones artísticas sería menor que en otro caso. Mises (2011a: 781) supone dudoso el derecho de propiedad intelectual: «son muchos los que consideran que estas propiedades carecen de base y justificación». Resumimos aquí las principales objeciones al concepto de propiedad intelectual:

a) Un objeto ideal -invención o idea- no es un bien económico pues proporciona servicios inagotables. No hay rivalidad en el uso y el consumo, en su caso, de un free rider no reduce el consumo de los creadores.

b) La actividad del creador o autor es similar a la de cualquier empresario; ambos disfrutan de los beneficios de ser los primeros en ofrecer sus creaciones al mercado. 
c) Imitar o copiar algo es legítimo y moral pues no se reduce ni la propiedad, ni el disfrute de los bienes por parte de sus dueños.

d) La legislación al respecto es arbitraria: (i) existen categorías no patentables tales como las verdades filosóficas, matemáticas o científicas. Unos productores reciben protección legal y otros no. (ii) Los derechos tienen una duración variable.

e) No es posible medir y comparar la utilidad de las leyes de propiedad intelectual frente a su ausencia. No hay evidencia de que los beneficios de la protección legal excedan a sus costes.

f) Existen patentes extravagantes. Los derechos de propiedad deben ser claramente visibles y objetivos.

g) Aceptabilidad social. Los consumidores, en general, desafían abiertamente la legislación sobre propiedad intelectual. Este hecho podría interpretarse (al menos) de dos maneras: (i) La inmensa mayoría de los consumidores exhibe una conducta inmoral; y (ii) Existe una duda razonable de la legitimidad de estos derechos y sobre la idea misma de «propiedad intelectual».

\section{La respuesta del mercado ante el free rider}

Ya hemos visto que el problema del free rider no es tan grave como parece pero, en ocasiones, la conducta de algunas personas puede ser antisocial y es la propia sociedad, dentro de la economía de mercado, quien encuentra las mejores soluciones. Dicho de otra forma, que el gobierno no pueda excluir del consumo a los que no pagan por un servicio público no significa que el mercado no pueda hacerlo. El mercado va encontrando soluciones, principalmente tecnológicas, ante cada problema. La TV en abierto era un bien público hasta que la invención de un decodificador de señal la convirtió en bien privado. Pero aunque no fuera posible excluir a los consumidores que no pagan por el servicio - caso de la radio o TV en abierto- existen soluciones de mercado como la financiación del servicio mediante el pago por publicidad. Analicemos las comunidades de propietarios, caso cotidiano donde abunda el free rider, y veamos cómo el mercado ha ido dando soluciones. Hace aproxima- 
damente 50 años $^{8}$ en España no existían los servicios de administración de fincas y correspondía a los presidentes y secretarios de cada comunidad su gestión y mantenimiento. Algunos vecinos esquivaban los cargos apelando a una supuesta falta de preparación técnica, otros tenían una avanzada edad, pero en general, el motivo principal era no querer asumir una responsabilidad ingrata y no remunerada. Casi nadie está dispuesto a trabajar «gratis» para el beneficio de los demás y casi todos prefieren que sea «otro» quien ejerza los cargos. Presidente y secretario debían trabajar en beneficio de todos por lo que la figura del free rider era muy frecuente, además, quienes ocupaban el cargo por sorteo podían ser negligentes sin recibir sanción alguna. Este problema ha sido resuelto, en gran medida, por los administradores de fincas sobre quienes recae el grueso del trabajo a cambio de unos honorarios profesionales que se pagan de forma alícuota por todos los comuneros. En España, hoy en día, la inmensa mayoría de comunidades de propietarios contrata administradores de fincas y las que no lo han hecho es, entre otros, por estos motivos: a) su reducido tamaño hace que el trabajo de los cargos de presidente y secretario sea despreciable; b) los propietarios asumen de forma responsable y rotatoria los cargos sin que el free rider constituya un problema reseñable; c) los propietarios que no desean ocupar cargos compensan económicamente el trabajo de aquellos otros que sí están dispuestos. En este caso, la compensación suele consistir en eximirlos del pago de la cuota mensual de mantenimiento.

Respecto a la propiedad intelectual, ¿cómo actúa el mercado para reducir las externalidades que sufren los productores? Si la tecnología, al alcance de los consumidores, permite realizar copias electrónicas de creaciones artísticas (música, literatura, cine) a coste marginal casi cero, es igualmente la tecnología la que hace posible que los free riders empiecen a pagar por aquello que consumen. La forma clásica es la publicidad, tal y como sucede en la radio y en la TV en abierto, pero existe otra forma muy interesante: añadir al producto una serie de utilidades tecnológicas que son altamente apreciadas por el cliente y venderlo todo junto. El resultado es el

${ }^{8}$ La primera ley de propiedad horizontal en España data de 1960 (Ley 49/1960, de 21 de julio). 
pago por un servicio de suscripción a precios módicos. Por ejemplo, la empresa Spotify ofrece la posibilidad de escuchar música "gratis con anuncios» o pagar 9,99€ al mes por un servicio premium sin anuncios y que ofrece mayor calidad de sonido, entre otras ventajas. La empresa Amazon ha inventado otro sistema: vende un reproductor -Kindle-que sólo es compatible con sus propios libros electrónicos. Sin descartar servicios premium, como Kindle Unlimited, que pone a disposición del lector más de un millón de títulos por sólo 9,99€ al mes. Otra ventaja de optar por servicios de pago es que los sistemas electrónicos permiten reproducir los contenidos en los diversos dispositivos que posee el cliente: libro electrónico, ordenador, tableta y teléfono móvil. Por último, existe otra forma más sutil en la que el mercado retribuye indirectamente al productor intelectual, aún en ausencia de la protección legal de sus derechos de autor. Nos referimos a la fama. Artistas, expertos, inventores, profesionales, etc. publican libremente sus creaciones en Internet y son retribuidos, a posteriori, de diferentes formas, en función del éxito otorgado por las audiencias. Los artistas son contratados para hacer actuaciones en vivo; expertos y académicos, que antes eran desconocidos, son ahora contratados para impartir conferencias; y los autores ya consagrados ven aumentar su caché y sus ingresos vía servicios de pago.

\section{La respuesta del gobierno ante el free rider}

Hasta ahora hemos visto que el free rider no constituye un problema económico para los productores, ni para los consumidores que pagan por el servicio. Insistimos que en nuestra definición, el free rider no utiliza la violencia ni el fraude y que su consumo no es a expensas de los pagadores. Resumiendo, el problema suscitado es un presunto lucro cesante del productor que, en definitiva, es el responsable de excluir a los consumidores que no pagan. También hemos visto que el mercado proporciona formas de retribuir a los productores (publicidad) sin tener que excluir a nadie o métodos que permiten discriminar a pagadores y gorrones. Estas soluciones se enmarcan en los procesos espontáneos y evolutivos de cooperación social. La respuesta del gobierno, en cambio, consiste en im- 
poner el pago coactivo de impuestos generalizados lo cual lleva asociado una serie de problemas que, con frecuencia, empeoran la situación.

La intervención del gobierno no sólo es antieconómica sino que tampoco resuelve satisfactoriamente el problema, más bien lo agrava. El gobierno cobrará impuestos a todos los contribuyentes para financiar una actividad abierta al público que no excluye a nadie; supuestamente todos pagan y todos pueden disfrutar del servicio que ahora se producirá de forma «más eficiente». En el ejemplo de los fuegos artificiales, el ayuntamiento confiscará una pequeña cantidad de dinero a cada contribuyente y podrá sufragar el mayor coste de una pirotecnia acorde a la «categoría» de la localidad y del pueblo, y a aquello considerado «socialmente deseable» (todavía desconocemos como se realiza el cálculo del «deseo social»). Según algunos economistas, esta solución aumenta la utilidad social mientras que el coste marginal del impuesto es muy reducido. Sin embargo, esta solución es antieconómica para el grueso de la población porque una parte de la población se verá obligada a sufragar un consumo que no valora o que no podrá disfrutar. Los fuegos artificiales se producen en un espacio y momento concretos, y sólo podrá disfrutarlos una pequeña parte de la población. El gobierno parece ignorar que el desplazamiento al lugar de exhibición es un coste considerable en tiempo y dinero, el cuál variará en función de las circunstancias personales de cada sujeto. Algunas personas no podrán disfrutar del evento público porque están de viaje, o enfermos, o cuidando a sus hijos pequeños, o trabajando, etc. Colectivizar el consumo en una fecha y lugar señalados no hace sino incrementar el número de excluidos involuntarios. No importa donde se elija quemar los fuegos artificiales, la mayoría de la población - que ha sufragado el evento con impuestos- queda excluida de forma indirecta. No se trata de una exclusión legal, pues a nadie se le impide acudir al espacio público, se trata de una exclusión económica debida al coste de oportunidad. Antes de la intervención, algunos vecinos del barrio pagaban voluntariamente por ver «sus» discretos fuegos artificiales desde su casa o desde la plaza; después de la intervención pagan casi todos pero razones espaciales (ubicación) y temporales (fecha) les impedirá o dificultará disfrutar del espectáculo. El gobierno no ha eliminado la 
externalidad sino que la ha modificado según su particular criterio y no se han resuelto los supuestos problemas que pretendía combatir. Sigue habiendo free riders pues hay muchos consumidores del espectáculo que no pagan impuestos. Cuando el gobierno recauda impuestos a toda la población para sufragar los fuegos artificiales produce una gran externalidad negativa, por pequeña que sea su importancia marginal; por otro lado, las externalidades positivas que causa la intervención no desaparecen sino que se transforman: a) aquellos consumidores dispuestos a pagar 10 o 20 por el espectáculo ahora sólo pagarán una cantidad mucho menor mediante sus impuestos; $b$ ) entre los consumidores del espectáculo se hallan necesariamente visitantes y turistas que no pagan impuestos en la localidad. Inevitablemente, la mayoría de contribuyentes sufrirá una merma de sus ingresos sin recibir nada a cambio y de esta manera, se restringe su utilidad ya sea en forma de consumo o de ahorro e inversión. Cualquier intervención en contra de los deseos de los consumidores es antieconómica en las esferas individual y social pues la medida reduce la cantidad de capital disponible en la sociedad.

Desde el punto de vista ético, es discutible afirmar la validez de cualquier medio que utilice la violencia para obtener un fin. No es lícito, por tanto, confiscar a muchos, por pequeña que sea la cantidad nominal, para beneficiar a unos pocos. Todo inicio injustificado de la violencia es inmoral, incluida cualquier forma de exacción fiscal. Todo impuesto es una redistribución de riqueza e ingresos. «La riqueza y el ingreso es tomado a la fuerza de sus propietarios y productores y transferido a personas que no eran dueños de riqueza y a quienes no producen estos ingresos» (Hoppe, 2016). Por último, la justificación de la intervención, a saber, que su resultado proporcionará eventualmente una mayor utilidad o un mayor cumplimiento del «deseo social» constituye en sí mismo una impostura, un acto de deshonestidad intelectual o, en el mejor de los casos, de un error metodológico inadmisible. 


\section{Conclusión}

La existencia de free riders en el libre mercado no constituye un problema reseñable ni para los productores, ni para los consumidores, ni para la sociedad en su conjunto. De hecho, todo el progreso humano no es sino una acumulación histórica de externalidades positivas donde cada generación disfruta de los logros (y sufre los errores) conseguidos por todas las anteriores. Hemos visto dos ejemplos, uno imaginario donde los propietarios de un edificio viven junto a un estadio de fútbol, y otro real, donde los habitantes de la isla de La Palma (Canarias) sufragan voluntariamente los gastos de los festejos populares, incluido los fuegos artificiales. Podríamos seguir imaginando, pari passu, una gran cantidad de situaciones particulares con diferentes empresas que operan en diferentes sectores de la economía y obtendríamos una infinidad de casos donde se producen externalidades positivas, negativas y neutras. Aún partiendo del análisis de tan sólo dos casos, y a sabiendas de que es arriesgado hacer generalizaciones, podemos extraer nueve hipótesis praxeológicas:

a) Toda actividad humana, productiva o de consumo, de alguna manera, visible o invisible, directa o indirectamente, en mayor o menor escala, produce algún tipo de externalidad positiva o negativa.

b) Distinguir quién es o no es un free rider es problemático por lo siguiente:

(i) El valor es subjetivo y no sabemos, a priori, cómo afectará una externalidad a los distintos individuos.

(ii) La externalidad es heterogénea ya que una misma actividad produce múltiples efectos, positivos y negativos, que actúan simultáneamente o secuencialmente en el espacio y el tiempo.

(iii) La externalidad es marginal pues tanto los fenómenos objetivos de la actividad como las percepciones subjetivas se producen con diferente grado e intensidad.

(iv) Tanto el signo como la intensidad de la externalidad es cambiante en el tiempo según los cambios en la producción (ej. tecnológicos) y según las cambiantes circunstancias de los receptores de la externalidad.

c) El consumo del free rider no reduce el consumo de los que han pagado por el servicio. 
d) Si el productor del servicio consiente o soporta la existencia del free rider inferimos, por su conducta revelada, que el segundo no constituye un problema significativo para el primero o que, en caso contrario, el coste de exclusión de los free riders excede al beneficio potencial.

e) El mercado desarrolla, de forma evolutiva, a la par de la tecnología, formas de exclusión del free rider.

f) La intervención coactiva del gobierno no elimina las externalidades positivas ni los free riders sino que transforma su naturaleza.

g) Es imposible hacer un cálculo de coste-beneficio social por dos motivos:

(i) Según lo expuesto en (2), el equipo de economistas e ingenieros sociales no puede hacerse con la información para realizar su trabajo. El problema al que se enfrentan es el mismo que el problema de la imposibilidad del cálculo económico en una economía socialista.

(ii) Aún en el hipotético caso de que se dispusiera de tal información, no es posible medir, sumar o restar las utilidades y desutilidades.

h) El free rider no ha convenido negocio alguno, ni ha suscrito contrato con el productor de la externalidad.

i) La intervención del gobierno para eliminar el efecto free rider, debido a los incentivos racionales de políticos y funcionarios, tenderá a un mayor consumo de capital en la sociedad y a reducir la tasa de capitalización.

Y cuatro hipótesis normativas:

j) Toda extracción violenta de la propiedad privada es ilegítima e inmoral, independientemente de quién la realice, del fin perseguido o de que la cantidad confiscada sea altamente marginal.

k) El free rider carece de responsabilidad jurídica pues su beneficio, caso de poder demostrarlo, no es imputable a una conducta intencional sino a la del causante de la externalidad.

1) No es imputable al free rider que el productor no quiera o no pueda excluir del consumo a aquellos que no han pagado y, por tanto, no es responsable de que el productor sufra presuntamente un lucro cesante. 
m) Si el gobierno obliga al free rider al pago de una externalidad positiva, por la misma razón, y de forma inversa, debería indemnizar a todos aquellos que, subjetivamente, consideran la actividad como una externalidad negativa.

\section{VIII \\ CONCLUSIONES}

Todos los argumentos de carácter económico y ético que intentan justificar el papel económico del estado son criticables por lo siguiente:

1. El modelo teórico de competencia perfecta y su corolario, los "fallos del mercado", constituye un ejemplo de cientismo y su origen fue una exigencia ineludible del positivismo económico. Imaginar una economía estática, en equilibrio, con un mercado «perfecto» donde muchas empresas del mismo tamaño producen el mismo bien al mismo precio, para luego concluir que la realidad es «imperfecta» constituye un grave error epistemológico que ha sido acuñado como la «falacia del nirvana». Si la economía es una ciencia descriptiva, no es admisible elaborar una teoría normativa y afirmar luego que la realidad está «equivocada». Tampoco está debidamente justificado que el gobierno, institución tan mundana, esté mejor dotada que el mercado para reparar sus supuestos «fallos».

2. La definición de monopolio como único productor de un cierto bien es problemática ya que sólo el consumidor puede distinguir entre dos tipos de bienes; tampoco quedan definidos los ámbitos espacial y temporal para determinar qué entendemos por monopolio. La idea de un precio de monopolio es ilusoria pues no podemos probar que una restricción de la producción y un aumento del precio conduzca necesariamente a obtener mayores beneficios. El monopolio es incompatible con el libre mercado y su única definición es la prohibición gubernamental del libre ejercicio de la función empresarial, excepto a una o varias empresas privilegiadas.

3. El argumento de la eficiencia social, que sirve de justificación al intervencionismo, presenta algunos inconvenientes. La utilidad 
es subjetiva y no es posible medir, sumar y restar utilidades individuales para alcanzar una utilidad agregada o social. Cualquier método empleado es necesariamente arbitrario. Solamente la libertad individual, en ausencia de coacción y fraude, puede aproximarnos a lo que habitualmente se entiende como «eficiencia o utilidad social».

4. Una externalidad es un fenómeno praxeológico, subjetivo, dinámico y heterogéneo en su naturaleza e intensidad. Existe una duda razonable sobre la validez de las patentes y derechos de autor y sobre el concepto mismo de «propiedad intelectual». El libre mercado, sometido a los principios generales del Derecho, dispone evolutivamente de recursos que pueden internalizar los efectos externos más relevantes en la economía. El gobierno, en su afán por «reparar» los fallos del mercado, es un gran productor de externalidades negativas en la sociedad.

5. La teoría de los bienes públicos es cuestionable desde sus propios postulados de no-excluibilidad y no-rivalidad. Todo bien económico, incluidos los paradigmáticos bienes públicos de defensa, seguridad y justicia, están sometidos a rivalidad en su consumo; por otro lado, siempre existen formas de exclusión del servicio a quienes no desean pagar. La teoría de los bienes públicos como justificación del papel económico del estado queda cuestionada cuando éste se dedica a proveer toda clase de bienes.

6. El comportamiento del free rider es impecable desde las ópticas económica, jurídica y ética. Al igual que las externalidades, y debido su naturaleza subjetiva, identificar al free rider puede resultar problemático. El free rider no representa un problema significativo para los productores de economías externas ni para la sociedad en su conjunto, y es el mercado, en todo caso, quien mejor desarrolla formas de exclusión. 


\section{REFERENCIAS BIBLIOGRÁFICAS}

Alfaro, J., GonzÁlez, C. y Pina, M. (2007): Economía y Organización de Empresas, Madrid, McGraw-Hill.

BAstos, M.A. (2005): «¿Puede la intervención estatal ser justificada científicamente? Una crítica». Procesos de Mercado, Vol. II, n. . 1, pp. 11 a 51.

BeL, G. (2004): «Estudios de Economía Aplicada», pp. 231-249, vol. 22-2.

Block, W. (1977): «Austrian Monopoly Theory: A Critique», en Journal of Libertarian Studies, Vol. I, No. 4, spring, pp. 271-279. UK, Pergamon Press.

- (1983): «Public Goods and Externalities: The Case of Roads», en Journal of Libertarian Studies, Vol. VII, No. 1, spring, pp. 1-34.

- (2012): Defendiendo lo indefendible, Innisfree, Kindle.

Bourne, R. (2013): «War is the Health of the State», John Calvin Jones. Recuperado en: http://wiki.zirve.edu.tr/sandbox/ groups/law/wiki/f0047/attachments/935b3/Bourne\%20 $1918 \% 20$ War $\% 20$ is $\% 20$ the $\% 20$ Health $\% 20$ of $\% 20$ the $\% 20$ State\%20A4.pdf?sessionID=d64a87d1f8f6777ec4c0b9bc159b054 ba1a810aa

Chodorov, F. (2002): «The Income Tax: Root of all Evil», Online edition, Ludwig von Mises Institute.

DemSETZ, H. (1969): «Information and Efficiency: Another Viewpoint», en Journal of Law \& Economics, Vol. 12, No. 1 (Apr.), pp. $1-22$.

EEMEREn, F. y GROOTENDORST, R. (2004): A Systemathic Theory of Argumentation: The Pragma-dialectical Approach, Kindle, Cambridge University Press.

Frank, R., Jennings, S. \& Bernanke, B. (2012): Principles of Micro Economics, Sidney, McGraw-Hill.

Hoppe, H. (2013): Una Teoría del Socialismo y el Capitalismo, Innisfree, Kindle.

- (2016): «Entrevista sobre impuestos a Hans-Hermann Hoppe». Recuperado en http://www.miseshispano.org/2016/01/entrevista-sobre-impuestos-a-hans-hermann-hoppe/.

Huerta De Soto, J. (1986): Lecturas de economía política I, Madrid, Unión Editorial. 
- (2009-2010): «Curso de Introducción a la Economía», URJC. Recuperado de http://www.anarcocapitalista.com/JHSLeccionesindice.htm

- (2010a): Socialismo, cálculo económico y función empresarial, Madrid, Unión Editorial 4. ${ }^{\mathrm{a}}$ ed.

- (2012): «La esencia de la Escuela Austriaca y su concepto de eficiencia dinámica», Revista de Economía ICE, marzo-abril 2012, N. ${ }^{\circ} 865$.

Hummel, J. (1990): «National Goods versus Public Goods: Defense, Disarmament and Free Riders». Review of Austrian Economics, Vol. 4, pp. 88-122.

KINSELLA, S. (2008): «Contra la propiedad intelectual», Ludwig von

Mises Institute. Recuperado en www.Mises.org.

KIRZNER, I. (1995): Creatividad, Capitalismo y Justicia Distributiva, Madrid, Unión Editorial.

Mankiw, G. (2007): Principios de Economia, Madrid, Thompson.

Mises, L. (1986): Planificación para la libertad y otros ensayos, Buenos Aires, Centro de Estudios para la Libertad.

- (2011a): La Acción Humana, Madrid, Unión Editorial, 10. a ed.

Proudhon, P. (2005 [1840]): ¿Qué es la Propiedad?, Buenos Aires, Utopía Libertaria.

Rızzo, M. (1979): Time, Uncertainty, and Disequilibrium, Lexington Books.

Rothbard, M. (2013a): El Hombre, la Economía y el Estado (vol. II), Madrid, Unión Editorial.

- (2013b): Poder y mercado, Guatemala, UFM, Kindle.

- (2016): «El mito de la eficiencia», Instituto Mises Hispano. http://www.miseshispano.org/2016/04/el-mito-de-la-eficiencia/\#_ftnref1

Samuelson, P. y Nordhaus, W. (2006): Economía, Méjico, McGraw Hill (18 edición)

Schumpeter, J. (2012): Historia del Análisis Económico, Barcelona, Ariel.

Smith, A. (2011): La Riqueza de las Naciones, Madrid, Alianza Editorial. 